CARDIOVASCULAR MEDICINE

\title{
Implications of plasma concentrations of adiponectin in patients with coronary artery disease
}

\author{
Y Nakamura, K Shimada, D Fukuda, Y Shimada, S Ehara, M Hirose, T Kataoka, K Kamimori, \\ S Shimodozono, Y Kobayashi, M Yoshiyama, K Takeuchi, J Yoshikawa
}

Heart 2004;90:528-533. doi: 10.1136/hrt.2003.011114

See end of article for authors' affiliations

Correspondence to: Dr Y Nakamura, Department of Internal Medicine and Cardiology, Osaka City University Medical School, 1-4-3, Asahi-machi, Ábeno-ku, Osaka, 545-8585, Japan; ynakamura@msic.med. osaka-cu.ac.jp

Accepted

26 September 2003
Objective: To investigate whether concentrations of plasma adiponectin constitute a significant coronary risk factor, with particular focus on the relation between plasma concentrations of adiponectin and the development of acute coronary syndrome (ACS).

Subjects and methods: Plasma concentrations of adiponectin were measured in 123 patients with coronary artery disease (CAD) and in 17 control participants. Patients were divided into three groups according to condition type: acute myocardial infarction (AMI) group ( $\mathrm{n}=59$ ), unstable angina pectoris (UAP) group ( $n=28$ ), and stable angina pectoris (SAP) group $(n=36)$.

Results: Plasma concentrations of adiponectin correlated negatively with body mass index $(r=-0.18$, $p<0.05)$, serum triglyceride $(r=-0.25, p<0.01)$, and fasting glucose concentrations $(r=-0.21$, $\mathrm{p}<0.05)$, but correlated positively with age $(r=0.26, \mathrm{p}<0.01)$, high density lipoprotein cholesterol concentrations $(r=0.35, p<0.01)$, and low density lipoprotein particle size $(r=0.37, p<0.01)$. Plasma concentrations of adiponectin in patients with ACS, in both the AMI and UAP groups, were significantly lower than those in patients with SAP and in the control group (ACS, 6.5 (3.0) $\mu \mathrm{g} / \mathrm{ml}$; SAP, $11.3(5.9) \mu \mathrm{g} / \mathrm{ml}$; control $12.8(4.3) \mu \mathrm{g} / \mathrm{ml} ; \mathrm{p}<0.01)$. Additionally, plasma concentrations of adiponectin in patients with $\operatorname{CAD}(7.9(4.6) \mu \mathrm{g} / \mathrm{ml}, \mathrm{p}<0.01)$ were significantly lower than in the control group. There were, however, no significant differences between patients with SAP and the control group $(p=0.36)$. Multiple logistic regression analysis showed that smoking, fasting glucose concentration, and low log adiponectin concentration correlated independently with the development of an ACS.

Conclusions: The findings suggest that measurement of plasma concentrations of adiponectin may be of use for assessing the risk of CAD and may be related to the development of ACS.
A diponectin is a collagen-like plasma protein produced specifically by adipose tissue and is abundantly present in the circulation. Plasma concentrations of adiponectin are reduced in the setting of obesity, ${ }^{1}$ in patients with non-insulin dependent diabetes mellitus, ${ }^{2}$ and in patients with coronary artery disease (CAD). ${ }^{3}$ A previous study detected adiponectin in the catheter injured vascular walls of rats but not in intact vascular walls. ${ }^{4}$ A separate study showed that plasma adiponectin accumulates in the subendothelial space of the vascular wall at an early phase of catheter injury and can be detected around macrophages in the injured human aorta at the site of a thrombus. ${ }^{5}$ These observations may suggest that adiponectin accumulates rapidly in the vascular wall when endothelial function is impaired and modulates the transformation of macrophages to foam cells in vivo. Despite these advances in understanding, the exact relation between plasma concentrations of adiponectin and acute coronary syndrome (ACS) remains unclear in clinical practice.

In contrast, the established evidence from more than one study suggests that small low density lipoprotein (LDL) particle size is a risk factor for CAD..$^{6-8}$ Plasma concentrations of small LDL particles are significantly lower in patients with CAD than in control patients. While this finding supports the accepted aetiology of atherosclerosis, ${ }^{9}$ the relation between plasma concentrations of adiponectin and LDL particle size has not been fully clarified. In this study, we prospectively investigated whether circulating concentrations of plasma adiponectin may constitute a significant coronary risk factor. We focused particularly on the relation between plasma concentrations of adiponectin and the incidence of ACS.

\section{METHODS \\ Patient population}

Our population of 123 consecutive patients with suspected CAD were admitted to Osaka City University Hospital between 1 March 2000 and 10 October 2000, and underwent diagnostic coronary angiography following chest pain or ischaemic changes on ECG. Patients were divided into three groups according to their specific condition: acute myocardial infarction (AMI), unstable angina pectoris (UAP), or stable angina pectoris (SAP).

There were 59 patients with AMI, all of whom were catheterised within 24 hours of the onset of chest pain. Diagnosis of AMI was based on clinical symptoms, ECG evidence (ST elevation of at least $0.1 \mathrm{mV}$ in two or more leads), coronary angiography findings (occlusion of a main coronary artery branch with TIMI (thrombolysis in myocardial infarction) grade flow of 0,1 , or 2 ), and serum creatine kinase concentrations (a more than twofold increase from the upper limit of the normal range). UAP was diagnosed in

Abbreviations: ACS, acute coronary syndrome; AMI, acute myocardial infarction; BMI, body mass index; CAD, coronary artery disease; ELISA, enzyme linked immunosorbent assay; $\mathrm{HDL}$, high density lipoprotein; LDL, low density lipoprotein; PAI-1, plasminogen activator inhibitor type 1; SAP, stable angina pectoris; TIMl, thrombolysis in myocardial infarction; UAP, unstable angina pectoris 
28 patients, defined from clinical symptoms, namely typical precordial chest pain of class IIB or IIIB in the Braunwald classification, ${ }^{10}$ from angiographic evidence (documented severe stenosis of $>75 \%$ in the American Heart Association classification in one or more principal coronary arteries), and from serum creatine kinase concentrations (no significant evidence of increase). SAP, which was observed in the remaining 36 patients, was defined based on patient symptoms, specifically typical precordial chest pain from cardiac ischaemia during exercise and from the findings of coronary angiography (documented severe stenosis of $>75 \%$ in the American Heart Association classification in one or more principal coronary arteries).

The reference group consisted of 17 control participants (without CAD). Patients who had major surgery or trauma, serious active infectious diseases, malignancies, and chronic inflammatory diseases including rheumatoid arthritis, osteoarthritis, and inflammatory bowel disease were excluded from the study. Prior written informed consent was obtained from all the patients. This study was conducted in accordance with the guidelines approved by the ethics committee at our institution.

LDL particle size, serum triglyceride concentrations, and plasma concentrations of adiponectin, total cholesterol, high density lipoprotein (HDL) cholesterol, LDL cholesterol, and plasma glucose were measured for all the patients. The following data were also obtained: age, sex, and the presence of coronary risk factors; cigarette smoking, hypertension (as defined by the Joint National Committee V), ${ }^{11}$ diabetes mellitus (as defined by the World Health Organization study group), ${ }^{12}$ hypercholesterolaemia (defined as a total cholesterol concentration $>5.72 \mathrm{mmol} / \mathrm{l})$, and obesity defined as a body mass index $\left(\mathrm{BMI}, \mathrm{kg} / \mathrm{m}^{2}\right)>25.0$.

\section{Measurement of plasma concentrations of adiponectin and LDL particle size}

Venous blood samples were obtained from all the patients on admission to the hospital. Plasma concentrations of total cholesterol, HDL cholesterol, LDL cholesterol, and glucose and serum triglyceride, were measured in samples collected after the patients had fasted overnight. Plasma concentrations of adiponectin were measured by solid phase enzyme linked immunosorbent assay (ELISA) ${ }^{13}$ with a commercially available kit (Otsuka Pharmaceutical Co, Japan). In this adiponectin assay, pretreated samples and serially diluted standard (recombinant human adiponectin) solutions were added to an appropriate number of wells of a microtitre plate and were incubated. The adiponectin in the sample is bound by the primary adiponectin monoclonal antibody immobilised in the well (first reaction). After washing, the secondary rabbit adiponectin antibody is added to each well and left to incubate (second reaction). The secondary rabbit adiponectin polyclonal antibody binds to the adiponectin trapped in the well in the first reaction. After washing, a conjugate of horseradish peroxidase and goat anti-rabbit IgG is added to each well and allowed to incubate (third reaction). The detection antibody recognises and binds to the rabbit adiponectin antibody trapped in the well in the second reaction. After further washing, the colorimetric substrate for the enzyme is added to all wells and incubated. The colour development is terminated by the addition of a stop solution. The intensity of the colour is measured at $450 \mathrm{~nm}$. Finally, the concentrations of the samples tested are calculated from the absorbance values of the adiponectin standard solutions assayed at the same time. LDL particle size was measured by gradient gel electrophoresis. ${ }^{14}$ Patients were classified into two groups on the basis of LDL peak particle size with $25.5 \mathrm{~nm}$ as the cut off diameter, as recommended by Austin and colleagues..$^{15}$

\section{Statistical analysis}

All data are expressed as mean (SD). Categorical variables were compared by the $\chi^{2}$ test. Differences in the mean values between groups were compared by an unpaired $t$ test or the Mann-Whitney $U$ test. The three groups were statistically compared by one way analysis of variance and post hoc multiple comparisons with Scheffe's test. Simple correlations between plasma concentrations of adiponectin and the value of other parameters were examined by Pearson's coefficient of correlation. Since the distribution of adiponectin was skewed, logarithmically transformed values were used for statistical analysis. Correlations between ACS and all other parameters were analysed first by simple logistic regression analysis and then by multivariate analysis. Multivariate adjusted odds ratios are presented with 95\% confidence intervals. Values of $\mathrm{p}<0.05$ were considered significant.

\section{RESULTS}

\section{Correlation between plasma concentrations of adiponectin and patient characteristics and metabolic parameters}

Plasma concentrations of adiponectin and LDL particle size were measured in our 123 patients with CAD (92 men and 31 women, mean (SD) age 65 (10) years) and in 17 control subjects ( 9 men and 8 women, mean (SD) age 61 (9) years). As figs 1 and 2 show, there was a negative correlation between plasma concentrations of adiponectin and BMI $(r=-0.18, \mathrm{p}<0.05)$ (fig $1 \mathrm{~A})$ and a positive correlation between plasma concentrations of adiponectin and LDL particle size $(r=0.37, \mathrm{p}<0.01)$ (fig 1B). Moreover, there was a positive correlation between plasma concentrations of adiponectin and age $(r=0.26, \mathrm{p}<0.01)$ (fig $\mathrm{lC})$. In terms of the lipid parameters, serum triglyceride concentrations were correlated negatively $(r=-0.25, \mathrm{p}<0.01)$ (fig 1D) and HDL cholesterol concentrations positively $(r=0.35$, $\mathrm{p}<0.01$ ) (fig $2 \mathrm{~A}$ ) with plasma concentrations of adiponectin. Total cholesterol concentrations and LDL cholesterol concentrations did not correlate with plasma concentrations of adiponectin ( $r=0.07, r=0.04$, respectively) (fig 2B, C). In addition, plasma glucose concentrations correlated negatively with plasma concentrations of adiponectin in patients with $\mathrm{CAD}(r=-0.21, \mathrm{p}<0.05)$ (fig 2D). However, no significant difference was observed between diabetic and non-diabetic patients with CAD (7.3 (3.9) g/ml $v 8.5$ (5.1) $\mu \mathrm{g} /$ $\mathrm{ml}, \mathrm{p}=0.17)$. Interestingly, there was a significant difference in plasma concentrations of adiponectin between men and women with CAD (6.5 (3.2) $\mu \mathrm{g} / \mathrm{ml} v 12.3$ (5.5) $\mu \mathrm{g} / \mathrm{ml}$, $\mathrm{p}<0.01$ ) (fig 3).

\section{Plasma concentrations of adiponectin in patients with CAD}

Next, we analysed the correlation between plasma concentrations of adiponectin in the three aetiologies of CAD (AMI, UAP, SAP) and in the control group (without CAD). Table 1 and table 2 show patient characteristics and a comparison of the metabolic parameters between patient subsets. There were no differences in terms of age, BMI, serum concentrations of triglyceride, total cholesterol, HDL cholesterol, LDL cholesterol, or LDL particle size between patients with AMI, UAP, and SAP. Although there were no differences in the number of diseased vessels between patients with AMI, UAP, and SAP, there was a significantly higher number of patients with single vessel disease within the AMI group ( $p<0.01$ ). As table 2 and fig 4 show, plasma concentrations of adiponectin in patients with AMI and UAP were significantly lower than those in patients with SAP and in control participants (both $\mathrm{p}<0.01$; AMI, 6.4 (2.7) $\mu \mathrm{g} / \mathrm{ml}$; UAP, 6.8 (3.7) $\mu \mathrm{g} / \mathrm{ml}$; SAP, $11.3(5.9) \mu \mathrm{g} / \mathrm{ml}$; control, 12.8 (4.3) $\mu \mathrm{g} / \mathrm{ml}$ ). 

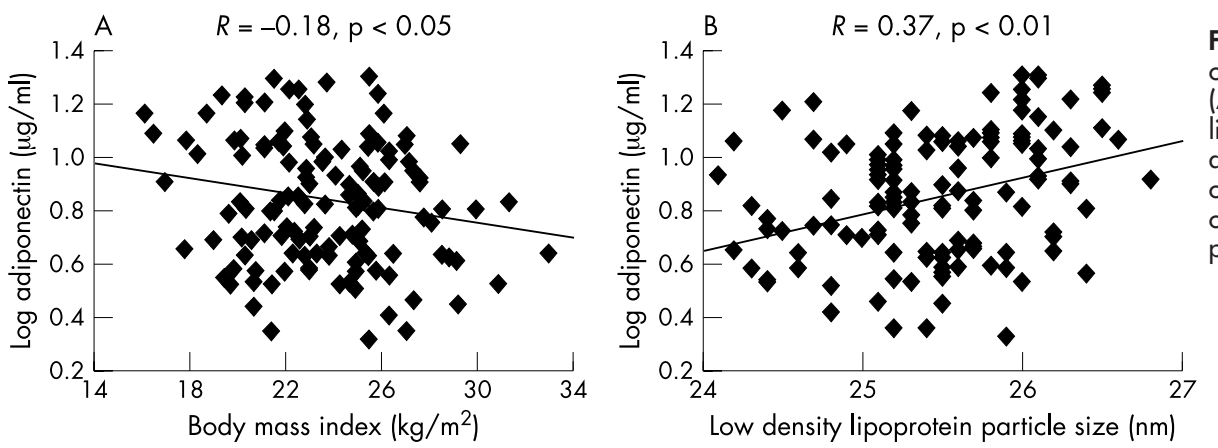

Figure 1 Correlation of plasma concentrations of adiponectin with (A) body mass index, (B) low density lipoprotein (LDL) particle size, (C) age, and (D) triglyceride. Plasma concentrations of adiponectin correlated with body mass index, LDL particle size, age, and triglyceride.
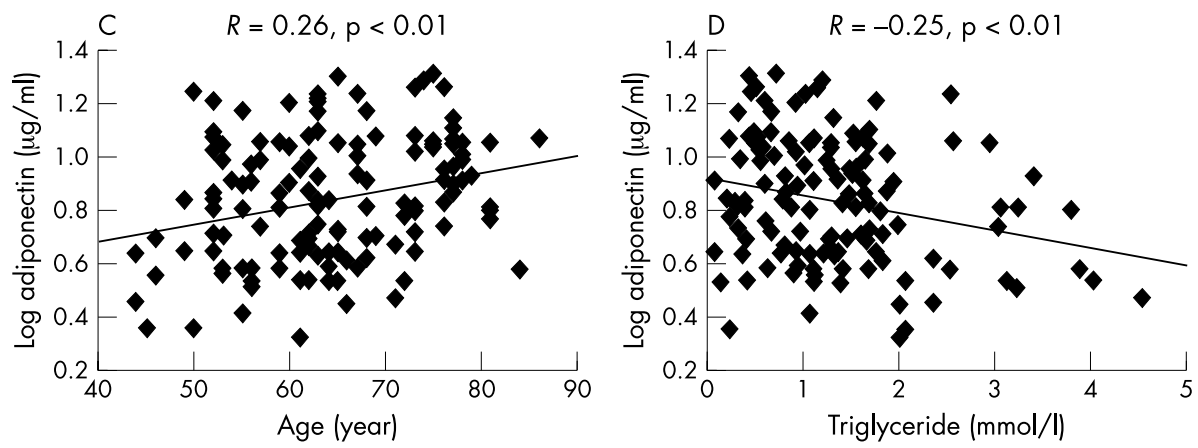

Table 3 shows the results of logistic regression analysis of ACS. Simple logistic regression analysis showed that the incidence of ACS correlated significantly with smoking, LDL particle size, fasting glucose, and log adiponectin concentrations in the study. Multiple logistic regression analysis of age, sex, BMI, smoking, HDL cholesterol, LDL particle size, fasting glucose, and log adiponectin concentrations showed that smoking, fasting glucose concentration, and low log adiponectin concentration correlated significantly and independently with the development of ACS $(\mathrm{p}<0.02)$.

\section{DISCUSSION}

In this study we have shown that plasma concentrations of adiponectin may be a useful parameter for the assessment of the risk of CAD and may be related to the development of ACS in the clinical setting.

\section{Plasma concentrations of adiponectin in patients with} ACS

In the present study, plasma concentrations of adiponectin were significantly lower in patients with AMI and UAP than in those with SAP, although patient background

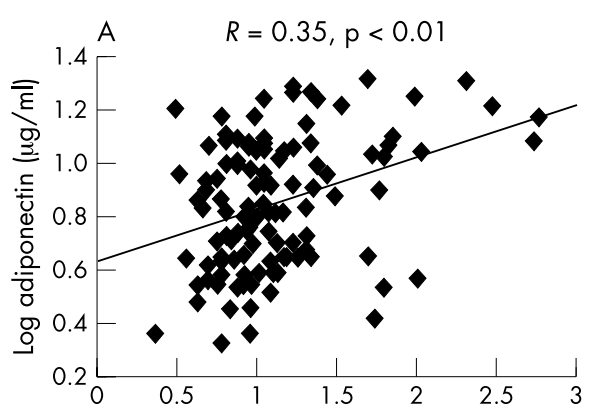

High density lipoprotein cholesterol ( $\mathrm{mmol} / \mathrm{I}$ )

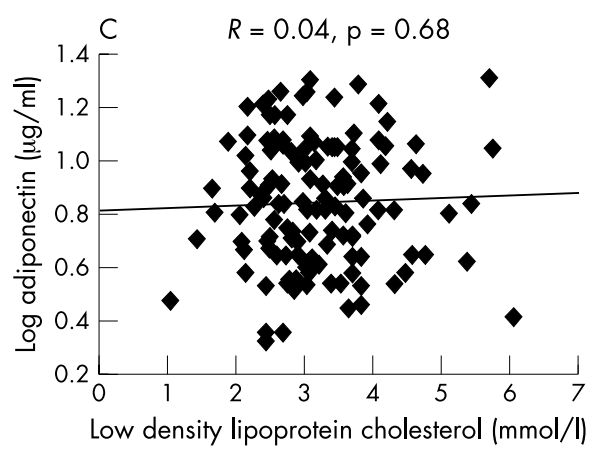

Figure 2 Correlation of plasma concentrations of adiponectin with (A) high density lipoprotein (HDL) cholesterol, (B) total cholesterol, (C) LDL cholesterol, and (D) fasting glucose. Plasma concentrations of adiponectin correlated with $\mathrm{HDL}$ cholesterol and fasting glucose concentrations. Total cholesterol concentrations and LDL cholesterol concentrations did not correlate with plasma concentrations of adiponectin.

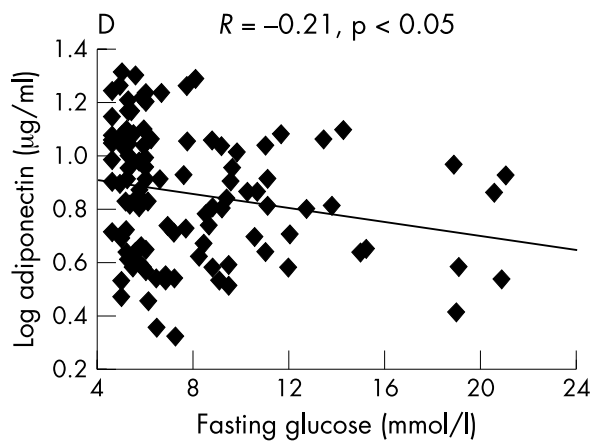




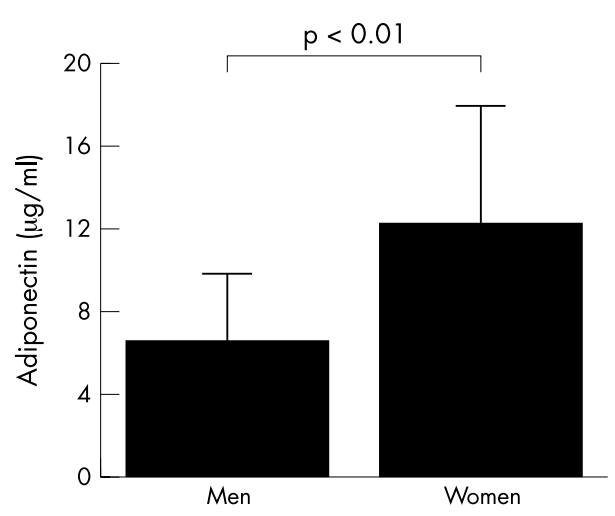

Figure 3 Plasma concentrations of adiponectin were significantly lower in men with coronary artery disease (CAD) than in women with CAD $(p<0.01)$ (see fig 4$)$.

characteristics such as age, BMI, and lipid parameters were comparable (tables 1 and 2). Additionally, considering AMI and UAP together as ACS, plasma concentrations of adiponectin were significantly lower in patients with ACS than in those with SAP and in the control group without CAD (ACS, 6.5 (3.0) $\mu \mathrm{g} / \mathrm{ml}$; SAP, $11.3(5.9) \mu \mathrm{g} / \mathrm{ml}$; without CAD $12.8(4.3) \mu \mathrm{g} / \mathrm{ml} ; \mathrm{p}<0.01$ ) (fig 4).

Adipose tissue is not simply an organ of energy storage but also a secretory organ producing a variety of bioactive substances, including leptin, tumour necrosis factor $\alpha$, plasminogen activator inhibitor type 1 (PAI-1), and adiponectin, that may contribute directly to the development of vascular disease. ${ }^{317-21}$ Adiponectin is abundantly present in the circulation and can be detected in injured vessels in both humans and animal models but not in intact vascular walls. ${ }^{45}$ Adiponectin decreases the expression of multiple adhesion molecules, including endothelial cells, through the modulation of nuclear factor $\kappa \mathrm{B}$ signalling. ${ }^{322}$ Adiponectin also dramatically suppresses the secretion of tumour necrosis factor $\alpha$ from human monocyte macrophages. ${ }^{23}$ Additionally, tumour necrosis factor $\alpha$ has stimulatory effects on PAI-1 release from adipocytes, ${ }^{24}{ }^{25}$ and plasma PAI-1 concentrations have been shown to correlate closely with visceral fat area but not with subcutaneous fat area in humans. ${ }^{19}$ Also, PAI- 1 has an important regulatory role in fibrinolytic processes and thrombus formation and, as a consequence, increased concentrations of plasma PAI-l are seen in survivors of myocardial infarction. ${ }^{26}$

In our study, plasma concentrations of adiponectin in patients with AMI and UAP were significantly lower than in

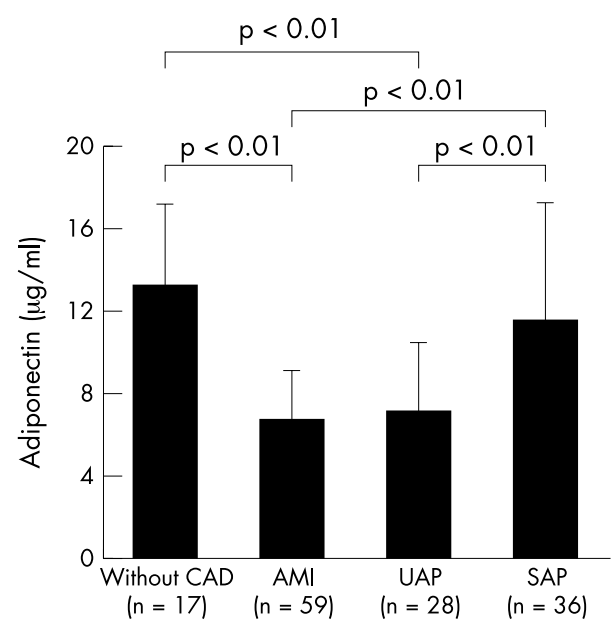

Figure 4 Graph showing plasma concentrations of adiponectin in patients with acute myocardial infarction (AMI), unstable angina pectoris (UAP), stable angina pectoris (SAP) and no coronary artery disease (CAD) (control group). Plasma concentrations of adiponectin in patients with AMI were significantly lower than those in patients with SAP and without CAD ( $<<0.01)$. In addition, plasma concentrations of adiponectin in patients with UAP were significantly lower than those in patients with SAP and without CAD $(p<0.01)$.

patients with SAP. In their study, Ouchi and colleagues ${ }^{522}$ suggested that adiponectin may act as an endogenous modulator of macrophage to foam cell transformation and endothelial inflammatory response. In addition, adiponectin may have antiatherosclerotic ${ }^{322}$ and anti-inflammatory properties. ${ }^{23}$ One explanation for this is that the inflammatory process may be accelerated in patients with low plasma concentrations of adiponectin. On the other hand, Zoccali and colleagues ${ }^{27}$ have shown that plasma concentrations of adiponectin in patients with end stage renal disease were lower in patients who experienced new cardiovascular events than in event-free patients; adiponectin may act as a protective factor against atherosclerosis in patients with end stage renal disease. Our own data show that, although there were no differences in the number of diseased vessels between AMI, UAP, and SAP groups, there was a significantly higher incidence of single vessel disease within the AMI group $(p<0.01)$. Furthermore, multiple logistic regression analysis of age, sex, BMI, smoking, HDL cholesterol concentration, LDL particle size, fasting glucose concentration, and log adiponectin concentration showed that smoking, fasting glucose, and low log adiponectin correlated independently with the development of ACS $(p<0.02)$.

\begin{tabular}{|c|c|c|c|c|c|}
\hline & AMI & UAP & SAP & Control & p Value \\
\hline Number & 59 & 28 & 36 & 17 & \\
\hline Age (years) & $64(11)$ & $64(9)$ & $67(10)$ & $61(9)$ & NS \\
\hline Men (\%) & 80 & 82 & 61 & 53 & NS \\
\hline Body mass index $\left(\mathrm{kg} / \mathrm{m}^{2}\right)$ & $24(3)$ & $23(3)$ & $23(4)$ & $23(3)$ & NS \\
\hline Hypertension (\%) & 44 & 57 & 56 & 24 & NS \\
\hline Hypercholesterolaemia (\%) & 52 & 50 & 44 & 29 & NS \\
\hline Diabetes mellitus (\%) & 53 & 32 & 50 & 29 & NS \\
\hline Smoking (\%) & 63 & 68 & 31 & 35 & 0.01 \\
\hline Obesity (\%) & 37 & 32 & 31 & 30 & NS \\
\hline Family history (\%) & 10 & 11 & 22 & 18 & NS \\
\hline \multicolumn{6}{|c|}{ Number of diseased vessels (\%) } \\
\hline One & 66 & 29 & 36 & & NS \\
\hline Two & 24 & 50 & 42 & & NS \\
\hline Three & 10 & 21 & 22 & & NS \\
\hline
\end{tabular}


Table 2 Comparison of metabolic parameters in patients with coronary artery disease

\begin{tabular}{|c|c|c|c|c|}
\hline & AMI & UAP & SAP & Control \\
\hline Adiponectin $(\mu \mathrm{g} / \mathrm{ml})$ & $6.4(2.7)$ & $6.8(3.7)$ & $11.3(5.9)^{* *}+\dagger$ & $12.8(4.3)^{* *}+\dagger$ \\
\hline Men & $6.0(2.5)$ & $5.6(2.7)$ & $8.4(4.2)^{*} \dagger$ & $10.4(3.6)^{* *}+\dagger$ \\
\hline Women & $8.0(3.0)$ & $12.4(2.6)$ & $15.9(5.4)^{* *}$ & $15.6(3.2)^{\star *}$ \\
\hline Total cholesterol $(\mathrm{mmol} / \mathrm{l})$ & $4.95(1.09)$ & $4.64(1.07)$ & $4.80(1.09)$ & $5.41(0.85)$ \\
\hline Triglyceride $(\mathrm{mmol} / \mathrm{l})$ & $1.33(0.80)$ & $1.33(1.06)$ & $1.44(0.91)$ & $0.91(0.60)$ \\
\hline $\mathrm{LDL}$ cholesterol (mmol/l) & $3.30(0.93)$ & $3.09(0.97)$ & $3.11(0.88)$ & $3.20(0.70)$ \\
\hline HDL cholesterol (mmol/l) & $1.04(0.27)$ & $0.94(0.29)$ & $1.03(0.25)$ & $1.79(0.57)^{\star *}+\dagger \ddagger$ \\
\hline LDL particle size $(\mathrm{nm})$ & $25.2(0.6)$ & $25.4(0.5)$ & $25.6(0.6)$ & $25.9(0.5)^{* *}$ \\
\hline Fasting glucose (mmol/l) & $9.66(4.60)$ & 7.31 (3.05) & $6.13(1.43)^{* *}$ & $5.75(1.14)^{\star *}$ \\
\hline
\end{tabular}

Value are mean (SD).

$\mathrm{HDL}$, high density lipoprotein; LDL, low density lipoprotein.

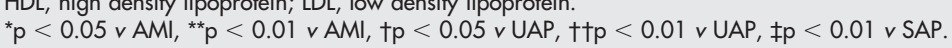

These data suggest that low plasma concentrations of adiponectin, a well known risk factor for CAD, are an independent variable for CAD, at least in the setting of ACS. Consequently, it is conceivable that low plasma concentrations of adiponectin may facilitate rupture of the atherosclerotic plaques, leading to ACS.

\section{Correlation between plasma concentrations of adiponectin and coronary risk factors}

Adiponectin is a collagen-like protein produced specifically by adipose tissue and is abundantly present in the circulation. In a previous study, the plasma concentrations of adiponectin in obese patients were shown to be significantly lower than those in non-obese patients, ${ }^{13}$ although adiponectin is secreted only from adipose tissue. Plasma concentrations of adiponectin are also significantly lower in patients with CAD than in age and BMI matched control patients. ${ }^{3}$ In the present study, there was a significant difference in plasma concentrations of adiponectin between patients with CAD and control patients (7.9 (4.6) $\mu \mathrm{g} / \mathrm{ml} v 12.8$ (4.3) $\mu \mathrm{g} / \mathrm{ml}$, $\mathrm{p}<0.01)$. However, there were no significant differences in plasma concentrations of adiponectin between patients with SAP and control patients (11.3 (5.9) $\mu \mathrm{g} / \mathrm{ml} v 12.8$ (4.3) $\mu \mathrm{g} / \mathrm{ml}$, $\mathrm{p}=0.36)$. A further point is that recent studies have reported that adiponectin mRNA expression was normalised or increased by thiazolidinediones in the adipose tissues of obese mice. ${ }^{28}$ Thiazolidinedione increases adiponectin concentrations independently of glycaemic control in humans and enhances adiponectin promoter activity. ${ }^{29}$ Patients in our SAP group had already been receiving some treatment with antianginal and antiatherosclerotic drugs, separate from thiazolidinediones. As certain medical treatments may confound interpretation of plasma concentrations of adiponectin measurement, there may be not significant differences in plasma concentrations of adiponectin between patients with SAP and control patients.

Another remarkable clinical finding in our study was that plasma concentrations of adiponectin were considerably increased in older and female patients with CAD. The reason for this may be that unstable plaques may stabilise as the patient grows older or that accumulation of adiponectin in atherosclerotic vascular walls may suppress its elimination half life from plasma, resulting in an increase in plasma concentrations of adiponectin in older patients with CAD. However, we cannot fully explain the reason.

The reason for the sex difference in plasma concentrations of adiponectin in the setting of CAD is not yet clear. A previous report documented that women normally have higher plasma concentrations of adiponectin than men. ${ }^{13}$ In this study, women with CAD had higher plasma concentrations of adiponectin than men with CAD (6.5 (3.2) $\mu \mathrm{g} / \mathrm{ml} v$ $12.3(5.5) \mu \mathrm{g} / \mathrm{ml}, \mathrm{p}<0.01)$. Sex hormones, including oestrogen, progesterone, and androgen, may affect plasma concentrations of adiponectin. Oestrogen in particular potentially has multiple beneficial effects on CAD. ${ }^{30}{ }^{31}$ However, all of the women in this study were postmenopausal, so the effect of sex hormones alone cannot account for sex difference in plasma concentrations of adiponectin. Another recent study suggests that adiponectin is found in two forms in serum: as a lower molecular weight trimer-dimer and a high molecular weight complex. There is also a sexual dimorphism in adiponectin concentrations and complex distribution. The vast majority of adiponectin in men is in the lower molecular weight form, whereas in women the two complexes are more

Table 3 Logistic regression analysis with acute coronary syndrome

\begin{tabular}{|c|c|c|c|c|c|c|}
\hline \multirow[b]{2}{*}{ Term } & \multicolumn{3}{|c|}{ Univariate } & \multicolumn{3}{|c|}{ Multivariate } \\
\hline & p Value & OR & $95 \% \mathrm{Cl}$ & p Value & OR & $95 \% \mathrm{Cl}$ \\
\hline Age & 0.46 & 0.98 & 0.94 to 1.03 & 0.62 & 1.02 & 0.95 to 1.08 \\
\hline Sex & 0.36 & 1.57 & 0.59 to 4.14 & 0.37 & 0.5 & 0.11 to 2.27 \\
\hline Body mass index & 0.27 & 1.08 & 0.94 to 1.23 & 0.93 & 0.99 & 0.82 to 1.20 \\
\hline Hypertension & 0.75 & 0.87 & 0.38 to 2.02 & & & \\
\hline Diabetes mellitus & 0.83 & 0.83 & 0.39 to 2.12 & & & \\
\hline Hyperlipidaemia & 0.59 & 1.26 & 0.54 to 2.93 & & & \\
\hline Smoking* & $<0.01$ & 4.01 & 1.63 to 9.88 & 0.01 & 4.46 & 1.44 to 13.87 \\
\hline Total cholesterol & 0.78 & 1.06 & 0.72 to 1.57 & & & \\
\hline Triglyceride & 0.72 & 0.92 & 0.58 to 1.46 & & & \\
\hline $\mathrm{HDL}$ cholesterol & 0.39 & 0.51 & 0.12 to 2.40 & 0.74 & 1.49 & 0.14 to 15.80 \\
\hline LDL cholesterol & 0.46 & 1.2 & 0.75 to 1.92 & & & \\
\hline LDL particle size & $0.02^{*}$ & $0.4^{*}$ & 0.19 to $0.85^{*}$ & 0.5 & 0.68 & 0.23 to 2.04 \\
\hline Log adiponectin* & $<0.01$ & 0.03 & 0.01 to 0.25 & 0.02 & 0.03 & 0.01 to 0.57 \\
\hline Fasting glucose* & $<0.01$ & 1.5 & 1.14 to 1.96 & 0.01 & 1.42 & 1.09 to 1.87 \\
\hline
\end{tabular}

*Significant parameters with single logistic regression analysis.

$\mathrm{Cl}$, confidence interval; OR, odds ratio. 
equally distributed. ${ }^{29}$ This structural difference may be caused by the sex difference in the plasma concentrations of adiponectin.

Plasma concentrations of adiponectin are reduced in patients with non-insulin dependent diabetes mellitus. ${ }^{2}$ Recent studies suggest that low plasma adiponectin may contribute to the pathogenesis of insulin resistance and diabetes mellitus in animals and humans. ${ }^{32} 33$ These findings suggest that adiponectin deficiency is implicated in the induction of insulin resistance in some circumstances and that this adipocyte derived protein may have a protective role against insulin resistance. In our study, plasma fasting glucose concentrations correlated negatively with plasma concentrations of adiponectin in patients with CAD $(r=-0.21, \mathrm{p}<0.05)$ (fig 2D). However, no significant differences were observed between diabetic and non-diabetic patients with CAD (7.3 (3.9) $\mu \mathrm{g} /$ $\mathrm{ml} v 8.5(5.1) \mu \mathrm{g} / \mathrm{ml}, \mathrm{p}=0.17)$. The reason for this may be that diabetic patients had already been receiving some treatment.

\section{Study limitations}

The present study had several limitations. There was a positive and negative correlation between plasma concentrations of adiponectin and some of the parameters shown in figs 1 and 2. However, although they generated significant $p$ values, the correlation coefficients themselves are rather weak. The reason may be the relatively small numbers of participants in the study population. Also, in this study, plasma concentrations of adiponectin were measured with solid phase ELISA $^{13}$ in a kit manufactured by Otsuka Pharmaceutical Co. This assay cannot distinguish between the lower weight trimer-dimer forms of adiponectin and the high molecular weight complexes, one of the factors associated with sex difference. Therefore, further investigations involving a larger number of patients distinguishing between men and women are required to confirm the validity of these results.

\section{Conclusion}

The present study showed that adiponectin is an important molecule associated with atherosclerosis in the clinical setting. Measurement of plasma concentrations of adiponectin may be a helpful adjunct for the assessment of the risk of CAD. Plasma concentrations of adiponectin may be related to the development of CAD, even in ACS.

\section{ACKNOWLEDGEMENTS}

We thank Tamami Ishii and Kanako Nitta for their secretarial assistance.

\section{Authors' affiliations \\ Y Nakamura, K Shimada, D Fukuda, Y Shimada, S Ehara, M Hirose, T Kataoka, K Kamimori, S Shimodozono, Y Kobayashi, M Yoshiyama, K Takeuchi, J Yoshikawa, Department of Internal Medicine and Cardiology, Osaka City University Medical School, Osaka, Japan}

\section{REFERENCES}

1 Matsuzawa Y, Funahashi T, Nakamura T. Molecular mechanism of metabolic syndrome $X$ : contribution of adipocytokines adipocyte-derived bioactive substances. Ann N Y Acad Sci 1999;892:146-54.

2 Hotta K, Funahashi T, Arita Y, et al. Plasma concentrations of a novel, adipose-specific protein, adiponectin, in type 2 diabetic patients. Arterioscler Thromb Vasc Biol 2000;20:1595-9.

3 Ouchi N, Kihara S, Arita Y, et al. Novel modulator for endothelial adhesion molecules: adipocyte-derived plasma protein adiponectin. Circulation 1999; 100:2473-6.
4 Okamoto $Y$, Arita $Y$, Nishida M, et al. An adipocyte-derived plasma protein, adiponectin, adheres to injured vascular walls. Horm Metab Res 2000;32:47-50.

5 Ouchi N, Kihara S, Arita Y, et al. Adipocyte-derived plasma protein, adiponectin, suppresses lipid accumulation and class $A$ scavenger receptor expression in human monocyte-derived macrophages. Circulation 2001; 103:1057-63.

6 Gardner CD, Fortmann SP, Krauss RM. Association of small low-density lipoprotein particles with the incidence of coronary artery disease in men and women. JAMA 1996;276:875-81.

7 Stampfer MJ, Krauss RM, Ma J, et al. A prospective study of triglyceride level, low-density lipoprotein particle diameter, and risk of myocardial infarction. JAMA 1996;276:882-8.

8 Lamarche B, Tchernof A, Mauriege P, et al. Fasting insulin and apolipoprotein $B$ levels and low-density lipoprotein particle size as risk factors for ischemic heart disease. JAMA 1998;279:1955-61.

9 Griffin BA, Freeman DJ, Tait GW, et al. Role of plasma triglyceride in the regulation of plasma low density lipoprotein (LDL) subfractions: relative contribution of small, dense LDL to coronary heart disease risk. Atherosclerosis 1994; 106:241-53.

10 Braunwald E, Unstable angina: a classification. Circulation 1989;80:410-4.

11 Anon. The fifth report of the Joint National Committee on Detection, Evaluation, and Treatment of High Blood Pressure (JNC V). Arch Intern Med 1993; 153:154-83

12 Anon. Diabetes mellitus. Report of a WHO Study Group. World Health Organ Tech Rep Ser 1985;727:1-113.

13 Arita Y, Kihara S, Ouchi N, et al. Paradoxical decrease of an adipose-specific protein, adiponectin, in obesity. Biochem Biophys Res Commun 1999;257:79-83.

14 Campos H, Genest JJ Jr, Bliilevens E, et al. Low density lipoprotein particle size and coronary artery disease. Arterioscler Thromb 1992;12:187-95.

15 Austin MA, Krauss RM. Genetic control of low-density-lipoprotein subclasses. Lancet 1986;ii:592-5.

16 Austin MA, Breslow JL, Hennekens $\mathrm{CH}$, et al. Low-density lipoprotein subclass patterns and risk of myocardial infarction. JAMA 1988;260:1917-21.

17 Hotamisligil GS, Shargill NS, Spiegelman BM. Adipose expression of tumor necrosis factor-alpha: direct role in obesity-linked insulin resistance. Science 1993;259:87-91.

18 Maeda K, Okubo K, Shimomura I, et al. Analysis of an expression profile of genes in the human adipose tissue. Gene 1997; 190:227-35.

19 Shimomura I, Funahashi T, Takahashi M, et al. Enhanced expression of PAI-1 in visceral fat: possible contributor to vascular disease in obesity. Nature Med 1996;2:800-3.

20 Spiegelman BM, Choy L, Hotamisligil GS, et al. Regulation of adipocyte gene expression in differentiation and syndromes of obesity/diabetes. J Biol Chem 1993;268:6823-6.

21 Zhang $Y$, Proenca R, Maffei $M$, et al. Positional cloning of the mouse obese gene and its human homologue. Nature 1994;372:425-32

22 Ouchi N, Kihara S, Arita Y, et al. Adiponectin, an adipocyte-derived plasma protein, inhibits endothelial NF-kappaB signaling through a cAMP-dependent pathway. Circulation 2000;102:1296-301.

23 Yokota T, Oritani K, Takahashi I, et al. Adiponectin, a new member of the family of soluble defense collagens, negatively regulates the growth of myelomonocytic progenitors and the functions of macrophages. Blood 2000;96:1723-32.

24 Birgel M, Gottschling-Zeller H, Rohrig K, et al. Role of cytokines in the regulation of plasminogen activator inhibitor-1 expression and secretion in newly differentiated subcutaneous human adipocytes. Arterioscler Thromb Vasc Biol 2000;20: 1682-7.

25 Gottschling-Zeller $\mathrm{H}$, Birgel $M$, Rohrig K, et al. Effect of tumor necrosis factor alpha and transforming growth factor beta 1 on plasminogen activator inhibitor- 1 secretion from subcutaneous and omental human fat cells in suspension culture. Metabolism 2000;49:666-71.

26 Hamsten A, Wiman B, de Faire U, et al. Increased plasma levels of a rapid inhibitor of tissue plasminogen activator in young survivors of myocardial infarction. N Engl J Med 1985;313:1557-63.

27 Zoccali C, Mallamaci F, Tripepi G, et al. Adiponectin, metabolic risk factors, and cardiovascular events among patients with end-stage renal disease. J Am Soc Nephrol 2002; 13:134-41

28 Maeda N, Takahashi M, Funahashi T, et al. PPARgamma ligands increase expression and plasma concentrations of adiponectin, an adipose-derived protein. Diabetes 2001;50:2094-9.

29 Pajvani UB, Du X, Combs TP, et al. Structure-function studies of the adipocytesecreted hormone Acrp30/adiponectin: implications for metabolic regulation and bioactivity. J Biol Chem 2003;278:9073-85.

30 Williams JK, Adams MR, Herrington DM, et al. Short-term administration of estrogen and vascular responses of atherosclerotic coronary arteries. J Am Coll Cardiol 1992;20:452-7.

31 Gilligan DM, Quyyumi AA, Cannon RO 3rd. Effects of physiological levels of estrogen on coronary vasomotor function in postmenopausal women. Circulation 1994;89:2545-51

32 Hu E, Liang P, Spiegelman BM. AdipoQ is a novel adipose-specific gene dysregulated in obesity. J Biol Chem 1996;271:10697-703.

33 Hotta K, Funahashi T, Bodkin NL, et al. Circulating concentrations of the adipocyte protein adiponectin are decreased in parallel with reduced insulin sensitivity during the progression to type 2 diabetes in rhesus monkeys. Diabetes 2001;50:1126-33 